\title{
OBSERVATIONS ON THE EFFECT OF NECTAR-ROBBERY ON THE REPRODUCTIVE SUCCESS OF AERANTHES ARACHNITIS (ORCHIDACEAE)
}

\author{
DAVID L. ROBERTS \\ Royal Botanic Gardens, Kew, Richmond, Surrey, TW9 3AB, UK. \\ d.roberts@kew.org
}

\begin{abstract}
While the presence of nectar is the most common floral reward offered by orchids, approximately one-third of orchid species have evolved mechanisms of deceit whereby the pollinator receives no reward. Lack of reward has been shown to have a significant negative effect on reproductive success in the Orchidaceae, however the phenomenon of nectar-robbery has been poorly studied. Here we investigate the effect of nectar-robbery induced deceit by invasive ants in the nectariferous orchid Aeranthes arachnitis. Fruiting success was found to be below $5 \%$ at three sites, including two conservation areas, compared with $48.5 \%$ at a site next to plantations. All the populations showed loss of floral nectar, ranging from $64.3 \%$ to $100 \%$ of flowers observed. Loss of nectar to robbers that do not facilitate pollination not only represents a cost to fruiting success but also a loss of a resource to the orchid through reabsorption of any excess. Using Bell's Theory of nectar concealment it is possible to determine the critical point, below which nectar-robbery negatively affects fruiting success. Based on related angraecoid orchids the proportion of nectar bearing flowers would, theoretically, need to be $70 \%$. The higher levels of reproductive success surrounded by plantations may due to the presence of the non-native Callistemon citrinus acting as nectar source, thus maintaining an increased local abundance of the pollinator. This has important implications for the conservation and management of Aeranthes arachnitis and other species, which rely on nectariferous pollinators, particularly when a nectar bearing species becomes essentially deceptive. The result suggests that management of this nectar-robbery induced deceptive species should involve the manipulation of rewarding species within the surrounding area.
\end{abstract}

KEY WORDS: Orchidaceae, Aeranthes arachnitis, ants, Bell's Theory, nectar-robbery, Orchidaceae, reproductive success.

\section{Introduction}

Pollinators visit flowers for potential rewards, these including oils, floral fragrances, pollen or floral nectar, with nectar being by far the most common reward in the Orchidaceae (van der Pijl \& Dodson 1966, Arditti 1992, Dressler 1993). In return, the orchids benefit from the movement of pollinia between flowers, however, the efficiency of this strategy varies since orchids are often pollinator-limited (Nilsson, 1992). Although the reward is the tangible benefit pollinators receive, they are usually attracted to the flower in the first place through advertisement (Proctor et al. 1996). Approximately one-third of orchids have, however, evolved mechanisms of deceit whereby the pollinator receives no reward (van der Pijl \& Dodson 1966, Ackerman
1984). Deception in orchid pollination is largely through either food foraging behaviour or sexual attraction, although occasionally territorial defence or habitat-choosing behaviour is used. This enigmatic loss of pollinator reward results in reduced attraction and visitation (Nilsson 1992).

The presence of a reward, such as nectar, has been shown, on average, to double the probability of fruit set in both temperate and tropical orchids, and reduce rarity in British orchids (Neiland \& Wilcock 1998). Production of such a reward is costly (Southwick 1984, Pyke 1991) and it may be reabsorbed in the Orchidaceae (Koopowitz \& Marchant 1998, Stpiczyńska 2003). Loss of nectar to visitors that do not facilitate pollination, therefore, represents a cost to fruiting success and drains resources from the orchid. Nectar robbery in orchids is known 
(Koopowitz \& Marchant 1998, Dressler 1990), with robbery by ants recorded in Comparettia falcata (Rodríguez-Robles et al. 1992) and Aerangis verdickii (Koopowitz \& Marchant 1998). This phenomenon has, however, been poorly studied in the Orchidaceae (Koopowitz \& Marchant 1998) and its effects on the individual are unknown. In some cases, robbery may occur due to habitat alteration resulting in a faunal imbalance (Nilsson et al. 1992).

The most common and obvious nectary is the floral spur, which is an extension of one of the perianth segments, most often the labellum as in the genus Angraecum (Dressler 1993, Neiland \& Wilcock 1995). Nectaries, however, can be shallow and external, as seen in genera such as Listera and many Pleurothallid species (Dressler 1993). Even with the vast array of reward systems seen in the Orchidaceae, the phenomenon of nectar concealment described by Bell (1986) is as yet unknown. Bell (1986) suggested that plants should produce a proportion of their flowers that do not contain any nectar. He predicted that the proportion of 'cheating' flowers would equal the discrimination time divided by the handling time of the insect visitor. It may, therefore, be possible to determine the critical point below which nectar-robbery negatively affects fruiting success.

During two years of field work in Mauritius, Aeranthes arachnitis (Thouars) Lindl. was observed to lack nectar until ants where observed foraging on newly opened flowers. The aim of the study is to determine the possible cause and effect of observed nectar loss in A, arachnitis by applying Bell's hypothesis.

\section{Material and methods}

Study species and sites - Aeranthes arachnitis is a relatively common, nectar-bearing, epiphytic/lithophytic species of orchid that is endemic to the Mascarene Islands in the western Indian Ocean (La Réunion, Mauritius and Rodrigues). In Mauritius, $A$. arachnitis is found at all altitudinal levels with the exception of the mossy forest of Mt. Cocotte, although it is most common in the lower dry forest such as that found at Bel Ombre. The species was studied at the following sites:

1. Mont Chat - Remnant dry coast forest on exposed ridge, highly invaded vegetation.
Located in the Bambous Mountain range on the east coast.

2. Bel Ombre - Fixon CMA (Conservation Management Area), weeded and fenced plot containing dry lowland forest.

3. Combo - Recently weeded plot containing dry lowland forest.

4. Brise Fer-CMA, weeded and fenced plot containing upland climax forest.

5. Gouly Fils - Forestry station near Grand Bassin, bordered on three sides by Pinus elliotii plantation and on the fourth by a tea plantation. Aeranthes arachnitis was found growing as an epiphyte on planted Calistemon citrata.

6. Mont Cimetière, Rodrigues - Highly degraded dry evergreen forest, with areas of exposed rock face (Aeranthes arachnitis var. balfouri S. Moore ex J. G. Baker).

Fruiting success - Measurements were taken after flowering, in some cases flowers that would have developed into fruits were recognised by the significant swelling of the ovary and unpollinated flowers had wilted or had been abscised, leaving an easily recognisable scar. Fruiting success for each species was calculated as the percentage of the number of fruits formed from the total number of flowers produced for each species.

Nectar analysis - Presence of nectar was determined in the field by back-lighting of the floral spur. Nectar was removed and quantified using a clean microcapillary tube, and then sugar content calculated using a hand-held refractometer.

Bell's Hypothesis - Bell (1986) predicted that the proportion of 'cheating' flowers would equal the discrimination time divided by the handling time of the insect visitor. Very little information is available regarding the discrimination and handling time of insect visitors to the Orchidaceae because of the general rarity of such visits, particularly for angraecoid orchids such as Aeranthes (Dressler 1990). Wasserthal (1997) studied the pollination of three species of long-spurred Angraecum under controlled conditions. These observations were used to calculate the theoretical optimum proportion robbery Aeranthes arachnitis can sustain. 
TABLE 1. Fruiting success and nectar presence in Aeranthes arachnitis at different sites.

\begin{tabular}{|c|c|c|}
\hline Sites & $\begin{array}{c}\text { Fruiting } \\
\text { Success (\%) }\end{array}$ & Nectar-Bearing (\%) \\
\hline Mont Chat & - & 0.0 \\
\hline Bel Ombre & $4.0( \pm 1.8)$ & $35.7( \pm 25.1)$ \\
\hline Combo & - & $20.0( \pm 35.1)$ \\
\hline Brise Fer & $5.0( \pm 9.6)$ & $5.0( \pm 9.6)$ \\
\hline Gouly Fils & $48.5( \pm 9.7)$ & 0.0 \\
\hline Mont Cimetière & $3.3( \pm 2.3)$ & $9.1( \pm 17.0)$ \\
\hline
\end{tabular}

\section{Results}

Fruiting success was found to be below 5\% at three sites, of which two are CMAs, compared with $48.5 \%$ at Gouly Fils. All the populations showed loss of floral nectar, ranging from $64.3 \%$ to $100 \%$ of flowers observed (Table 1). Due to the difficulty in locating nectar-bearing flowers, since most had their nectar removed, floral spurs were found to contain $10 \mu \mathrm{l}$ with an average nectar sugar content of $14.5 \%$ based on four flowers from four separate plants. Based on times recorded by Wasserthal (1997) for three species of long-spurred Angraecum under controlled conditions, the proportion of nectar bearing flowers would, theoretically, need to be over $70 \%$ (Table 2).

On $4^{\text {th }}$ February 2000 , ant activity was observed on the flowers of Aeranthes arachnitis at the Fixon CMA, Bel Ombre, particularly in the floral spurs. Within three days all floral nectar had been removed and ant activity had ceased (Roberts \&
McGlynn 2004). No damage to the floral spurs was observed, unlike the observation of Aerangis verdickii by Koopowitz and Marchant (1998). Four species of ants were found in the floral spurs of Aeranthes arachnitis at the Fixon CMA, Bel Ombre (Pheidole megacephala Forel, Technomyrmex albipes Mann, Tetramorium insolens Smith and Solenopsis mameti Donisthorpe (prov. det.)) of which only one was found to be native (Roberts \& McGlynn 2004). Around 44 species of ants have been recorded from Mauritius (Fisher 1997, Roberts \& McGlynn 2004). Of these, approximately 24 are thought to be non-native, based on Fisher (1997) and McGlynn (1999), although this figure is likely to increase as we gain more knowledge of their distribution.

\section{Discussion}

Loss of nectar to visitors that do not facilitate pollination not only represents a cost to fruiting success but also a loss of a resource to the orchid. Nectar-robbery by ants has been record in Comparettia falcata in only five cases (RodríguezRobles et al. 1992), but in Aerangis verdickii 62\% of flowers had been robbed of their nectar (Koopowitz \& Marchant 1998). However, the full significance of resource loss does not seem to have been considered. Ants can also have an indirect negative effect on orchids through their well-known tendering behaviour. This has been shown to occur in Schomburgkia tibicinis where the ant-mealybug interaction decreased reproductive fitness (RicoGray \& Thien 1989). Such behaviour was observed on Mauritius and Rodrigues with aphids, mealybugs and scale insects, particularly in degraded habitats,

TABLE 2. Theoretical proportion of nectar bearing flowers in two species of Angraecum based on visitation times recorded by Wasserthal (1997).

\begin{tabular}{|c|c|c|c|}
\hline Species & $\begin{array}{c}\text { Discrimination } \\
\text { Time }^{1} \text { (sec.) }\end{array}$ & $\begin{array}{c}\text { Handling Time } \\
\text { (sec.) }\end{array}$ & $\%$ nectar bearing ${ }^{2}$ \\
\hline A. sesquipedale & $1.7-2.3$ & 7.9 & $70.9-78.5$ \\
\hline A. sororium & 1.0 & 3.4 & 70.6 \\
\hline
\end{tabular}

${ }^{1}$ Discrimination time based on visitation and unsuccessful pollinaria removal times.

${ }^{2}$ Calculated as for Bell (1986). 
but this requires further investigation (pers. obs.). However, the results presented here are based on observations, further work is required using ant exclusion experiments.

Both Angraecum sesquipedale and A. sororium, two of the three angrecoid species studies by Wasserthal (1997), are extremely long-spurred species with a labellum that acts as a landing platform. Aeranthes arachnitis has in contrast a short, wide spur and the orientation of the labellum probably prevents a hawkmoth from landing and therefore probably pollinated by hawkmoths in flight. It is difficult to determine whether $30 \%$ represents a threshold of nectarless flowers due to the differences in floral morphology. Even so, the $70-100 \%$ nectar loss represents a considerable loss to the orchid, not only in potential reproductive success but also in lost resource since it has been shown that nectar is reabsorbed in other orchid species (Koopowitz \& Marchant 1998). A considerable difference is seen in observed fruiting success compared with that predicted by Neiland and Wilcock (1998) for nectariferous species, and the possible threshold of nectarless flowers calculated using Bell's hypothesis of "cheating" flowers (Table 2). This suggests that the causal mechanisms that predispose orchids to an evolutionary trend of deception (Nilsson 1992), in this case, may not be present.

Hawkmoths are not completely dependent on sphingophilous flowers although there is a selective advantage of sphingid proboscis length in feeding (Wasserthal 1997). It has been suggested that in Madagascar the baobabs, Adansonia rubrostipa and $A$. $z a$, [with their brush-like anthers] which are pollinated by Coelonia solani, may offer an important nectar source for long-tongued hawkmoths since most of their nectar is not withheld (Baum 1995). However, sphingophilous flowers probably provide a more reliable nectar source than less specialised flowers, which can be exploited by other animals. This reliability may become more critical in seasons of general flower scarcity (Grant 1983, Wasserthal 1997). It is therefore possible that, at Gouly Fils, Callistemon citrinus acts a nectar source, thus maintaining an increased local abundance of the pollinator (the magnet species effect)
(Johnson et al. 2003) and resulting in a considerably higher level of fruiting success in Aeranthes arachnitis compared with other locations. Callistemon citrinus has been shown to be an important nectar source for the nectariferous birds since the brush-like flowers exclude some visitors, in particular the introduced honey bee which is a serious competitor on Mauritius (Hansen et al. 2002).

\section{Conclusions}

Invasive species may soon surpass habitat loss as the main cause of ecological disintegration globally and are probably already the main cause of extinctions in island ecosystems (Vitousek et al. 1997, Chapin et al. 2000, Clout \& Veitch 2002). Thus invasive species pose a major challenge to conservationists, their impact can extend to all trophic levels and have both direct and indirect effects. While habitat conversion and fragmentation are often recognized as the most significant threat to the protection of biological diversity, the ability of invaders to penetrate into undisturbed environments is particularly insidious because it is difficult to prevent (IUCN 2000).

Ferdy et al. (1999) developed a model of pollinator-induced density dependence in orchids that use deceit has suggested that survival of such species is not only dependant on population size but also on competition within and between patches. In this case, the two types of competition are the relative abundance of the rewarding species, since species such as bumblebees have been shown to choose the most common (Ferdy et al. 1999) or most conspicuous species (Larson \& Larson 1990), and competition between patches. The results suggest that management of deceptive species should involve control of rewarding species within a good patch (i.e. patches with high abundance of nectar rewarding species), with good patches distantly separated by lower quality patches. Situations where "competition between patches is not too strong but also when the resource levels are high enough to ensure the survival of pollinators at high density" would favour deceptive species (Ferdy et al. 1999). This has important implications for the conservation and 
management of Aeranthes arachnitis and other species, which rely on nectariferous pollinators, particularly when a nectar bearing species becomes essentially deceptive.

ACKNOWLEDGEMENTS. This work was funded as part of a project on the "Reproductive biology and conservation of the orchids of Mauritius" by the Guy Harvais Studentship for Orchid Research at the University of Aberdeen. I would also like to thank the National Parks \& Conservation Service and Mauritian Wildlife Foundation for logistical support, and the comments of an anonymous reviewer.

\section{LITERATURE CITED}

Ackerman, J.D. 1984. Pollination of tropical and temperate orchids. Pp. 98-101 in: K.W. Tan (ed.), Proceedings of the $11^{\text {th }}$ World Orchid Conference. American Orchid Society, Miami, Florida.

Arditti, J. 1992. Fundamentals of orchid biology. John Wiley and Sons, New York.

Baum, D.A. 1995. The comparative pollination and floral biology of baobabs (Adansonia- Bombacaceae). Ann. Missouri Bot. Gard. 82 : 322-348.

Bell, G. 1986. The evolution of empty flower. J. Theor. Biol. 118 : 253-258.

Chapin, F.S., E.S. Zavaleta, V.T. Viner, R.L. Naylor, P.M. Vitousek, O.E. Sala, H.L. Reynolds, D.U. Hooper, M. Mack, S.E. Diaz, S.E. Hobbie \& S. Lavorel. 2000. Consequences of changing biodiversity. Nature 405 : 234-242.

Clout, M.N. \& C.R. Veitch. 2002. Turning the tide of biological invasion: the potential for eradicating invasive species. Pp. 1-3 in: C.R. Veitch \& M.N. Clout (eds.), Turning the tide: the eradication of invasive species. IUCN, Gland, Switzerland.

Dressler, R.L. 1990. The Orchids: natural history and classification. Harvard University Press, Cambridge.

Dressler, R.L. 1993. Phylogeny and classification of the orchid family. Cambridge University Press, Cambridge, Mass.

Grant, V. 1983. The systematic and geographical distribution of hawk-moth flowers in the temperate north American flora. Bot. Gaz. 144 : 439-449.

Ferdy, J.-B., F. Austerlitz, J. Morat, P.-H. Gouyon \& B. Godelle. 1999. Pollinator-induced density dependence in deceptive species. Oikos $87: 549-560$.

Fisher, B.L. 1997. Biogeography and ecology of the ant fauna of Madagascar (Hymenoptera: Formicidae). J. Nat. Hist. $31: 269-302$.

Hansen, D.M., J.M. Olesen \& C.G. Jones. 2002. Trees, birds and bees in Mauritius: exploitative competition between introduced honey bees and endemic nectarivorous birds? J. Biogeogr. 29 : 721-734.

IUCN 2000. Guidelines for the prevention of biodiversity loss due to biological invasion. IUCN, Gland, Switzerland.

Johnson, S.D., C.I. Peter, L.A. Nilsson \& J. Agren. 2003. Pollination success in a deceptive orchid is enhanced by co-occurring rewarding magnet plants. Ecology 84 : 2919-2927.

Koopowitz, H. \& T.A. Marchant. 1998. Postpollination nectar reabsorption in the African epiphyte Aerangis verdickii (Orchidaceae). Amer. J. Bot. 85 : 508-512.

Larson, K.S. \& R.J. Larson. 1990. Lure of the locks: Showiest Ladies-tresses Orchids, Spriranthes romanzoffiana, affect bumblebee, Bombus spp., foraging behavior. Canad. Field Natur. 104 : 519-525.

McGlynn, T.P. 1999. The worldwide transfer of ants: geographical distribution and ecological invasion. J. Biogeogr. 26 : 535-548.

Neiland, M.R.M. \& C.C. Wilcock 1995. Maximisation of reproductive success by European Orchidaceae under conditions of infrequent pollination. Protoplasma 187 : 39-48.

Neiland, M.R.M. \& C.C. Wilcock 1998. Fruit set, nectar reward, and rarity in the Orchidaceae. Amer. J. Bot. 85 : 1657-1671.

Nilsson, L.A. 1992. Orchid pollination biology. Trends Ecol. Evol. 7 : 255-259.

Nilsson, L.A., E. Rabakonandrianina, R. Razananaivo \& J.-J. Randriamanindry. 1992. Long pollinia on eyes: hawk-moth pollination of Cynorkis uniflora Lindley (Orchidaceae) in Madagascar. Bot. J. Linn. Soc. 109 : 145-160.

van der Pijl, L. \& C.H. Dodson. 1966. Orchid flowers: their pollination and evolution. University of Miami Press, Coral Gables, Florida.

Proctor, M., P. Yeo \& A. Lark. 1996. The natural history of pollination. Harper Collins Publishers.

Pyke, G.H. 1991. What does it cost a plant to produce floral nectar? Nature $350: 58-59$.

Rico-Gray, V. \& L.B. Thien. 1989. Ant-mealybug interaction decreases reproductive fitness of Schombugkia tibicinis (Orchidaceae) in Mexico. J. Trop.Ecol. 5 : 109112.

Roberts. D.L. \& T.P. McGlynn. 2004. Tetramorium insolens Smith (Hymenoptera: Formicidae): a new record for Mauritius, Indian Ocean. Afr. Entom. 12 : 265-267.

Rodríguez-Robles, J.A., J. Meléndez \& J.D. Ackerman. 1992. Effects of display size, flowering phenology, and nectar availability on effective visitation frequency in 
Comparettia falcata (Orchidaceae). Amer. J. Bot. 79 : 1009-1017.

Southwick, E.E. 1984. Photosynthate allocation to floral nectar: a neglected energy investment. Ecology 65 : 1775-1779.

Stpiczyńska. M. 2003. Nectar resorption in the spur of Platanthera chlorantha Custer (Rchb.) Orchidaceae structural and microautoradiographic study. P1. Syst. Evol. 238 : 119-126.
Vitousek, P.M., C.M. D'Antonio, L.L. Loope, M. Rejmanek \& R. Westbrooks. 1997. Introduced species: a significant component of human-caused global change. New Zeal. J. Ecol. 21 : 1-16.

Wasserthal, L.T. 1997. The pollinators of the Malagasy Star Orchids Angraecum sesquipedale, A. sororium and A. compactum and the evolution of extremely long spurs by pollinator shift. Bot. Acta $110: 343-359$. 